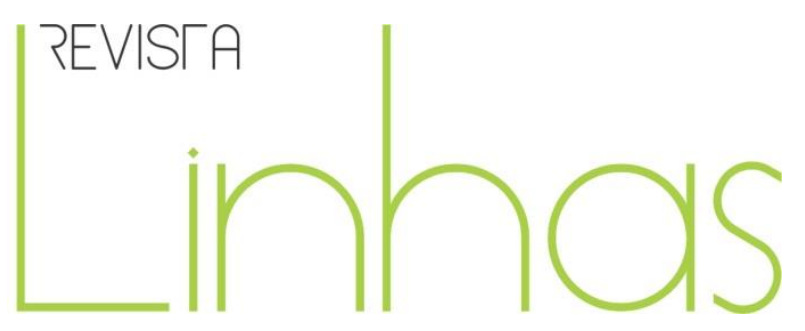

\title{
Resenha do livro "Desafios da educação sexual: interfaces pertinentes com a comunicação e tecnologia"
}

BRUNS, Maria Alves de T.; MELO, Sonia Maria M. (Orgs.) Desafios da educação sexual: interfaces pertinentes com a comunicação e tecnologia. Curitiba: CRV, 2016.

\section{Mônica Wendhausen}

Atua na Secretaria de Educação da Prefeitura Municipal de Florianópolis. Doutoranda em Educação pela Universidade do Estado de Santa Catarina - UDESC monicawendhausen@gmail.com

\section{Silvio Luiz Indrusiak Weiss}

Professor no Centro Universitário Municipal de São José - USJ. Doutor em Ciências do Movimento Humano pela Universidade do Estado de Santa Catarina - UDESC

silvioliw@gmail.com

\section{Para citar esta resenha:}

WENDHAUSEN, Mônica; WEISS, Silvio Luiz Indrusiak. Resenha do livro "Desafios da educação sexual: interfaces pertinentes com a comunicação e tecnologia". Revista Linhas. Florianópolis, v. 17, n. 33, p. 338-343, jan./abr. 2016. 
Refletindo dialogicamente dois temas emergentes relacionados ao âmbito educacional e escolar nesses primeiros anos do novo milênio, a saber: educação sexual e tecnologias digitais, o livro "Desafios da educação sexual: interfaces pertinentes com a comunicação e tecnologia", organizado pelas pesquisadoras Profa ${ }^{a}$ Dra $^{\mathrm{a}}$. Maria Alves de Toledo Bruns (USP) e Prof ${ }^{a}$. Dra . Sonia Maria Martins de Melo (UDESC), publicado em 2016 e contendo 240 páginas, está estruturado com um prefácio do Prof. Dr. Samuel Mendonça, coordenador do PPG em Educação da PUC - Campinas e mais dez capítulos com autorias diferentes, incluindo os capítulos assinados pelas organizadoras, e abordando diversos temas dessa complexa e original proposta que é estabelecer relações entre educação sexual e TIC na práxis pedagógica.

Os capítulos desta obra, em sua maioria, reúnem pesquisas acadêmicas, estudos de casos e relatos de experiências em diversos temas da área, envolvendo segmentos socioculturais os mais diversos, incluindo alunos de educação básica, educação superior e profissionais da educação em processo de formação continuada. Os estudos desenvolvidos pelos pesquisadores-autores concentram-se na Região Sul do Brasil e no estado de São Paulo, sendo os restantes configurados como ensaios teóricos acerca da temática em questão.

Deve-se salientar que a obra como um todo revela a busca por uma educação com perspectiva intencional e emancipatória, alinhando-se com o pensamento do educador Paulo Freire, quando afirma: “[...] ninguém educa ninguém, ninguém educa a si mesmo, os homens se educam entre si, mediatizados pelo mundo [...]" (FREIRE, 1987, p. 39), frase emblemática que marca esta obra, pois busca a emancipação dos seres humanos por meio de práticas de liberdade, em que todos aprendem juntos.

Nesse sentido, identificam-se nesse livro importantes pontos de convergência como a constatação, e isso deve servir de alerta, acerca da ausência de uma discussão política e coerente em relação à dimensão "sexualidade" ao longo da formação inicial e continuada para os professores, vista nesta obra como uma dimensão do existir humano, bem como a sua interface com as novas tecnologias da informação e comunicação, meios de comunicação e os interesses que movem o uso massivo das crianças, adolescentes e jovens. 
Outro ponto importante é o fomento de práticas pedagógicas dialógicas e, por isso, reflexivas que potencializem o que os alunos/as têm a dizer sobre a dimensão sexualidade e os desafios cotidianos. Por último, a obra enfatiza a dimensão sexualidade vista como mote de decisões e escolhas políticas que ultrapassam as concepções binárias, sexistas e reducionistas, revelando que as manifestações da sexualidade estão na forma como produzimos a vida, numa sociedade caracterizada como da informação e por isso, imersa num mundo digital, proporcionando outras leituras de mundo.

No primeiro capítulo, as autoras Patrícia J. Moreira e Ademilde S. Sartori apresentam os resultados de uma pesquisa realizada junto a jovens frequentadores de lan houses, em Florianópolis, propondo uma discussão sobre a adaptação desse modelo à escola, que chamam de LanEscola. A proposta das autoras aponta a necessidade de uma visão crítica sobre o uso feito pelos jovens/adolescentes das tecnologias digitais nos mais diversos espaços, inclusive na instituição escolar e, a partir daí, refletir sobre o papel do professor na sua aplicação meramente instrumental e técnica, não considerando as experiências/vivências desses sujeitos.

O capítulo dois, com autoria de Gabriela Maria D. de Carvalho, é um ensaio acerca da complexidade engendrada pela mídia televisiva na transmissão de valores/conceitos hegemônicos, principalmente os ligados aos padrões de gênero e comportamentos relacionados à sexualidade. A autora propõe utilizar-se dessa ferramenta e dos programas televisivos para dialogar sobre educação sexual com adolescentes na escola, enfatizando a importância de uma "escuta" despida de preconceitos no que diz respeito às questões levantadas pelos/as adolescentes/telespectadores, consumidores dos programas televisivos da TV aberta, principalmente as telenovelas no processo educativo.

Com ampla fundamentação e um relato de pesquisa realizado sobre o uso de blogs nas escolas de Florianópolis, o capítulo três, com autoria de Raquel Regina Z. V. Schöninger e Ademilde S. Sartori, propõe o uso dos blogs como prática pedagógica dialógica e interativa, na medida em que ultrapasse a mera postagem de acontecimentos ou atividades realizadas no ambiente escolar, sendo visto como espaço de encontro entre sujeitos, caracterizando-se como uma ferramenta/instrumento que potencializa a construção de novos saberes, cooperativa e colaborativamente, possibilitando assim a 
construção de ambiências comunicativas no processo de ensino e aprendizagem entre os sujeitos envolvidos. Dessa forma, a comunicação de uma informação não se restringe a 'comunicar o outro', mas sim, produzir, como as autoras propõem, significado significante para ambos, receptor e emissor.

No capítulo quatro, Andreza Leão, Carla Silva, Gabriel Ferreira e Paulo Ribeiro relatam o processo de planejamento, implementação e execução de um curso de formação continuada, modalidade a distância, voltado à educação sexual, para acadêmicos de Pedagogia da UNESP, utilizando a Plataforma MOODLE. O curso chama a atenção para o importante papel das TIC para oportunizar espaços de reflexão, aprendizado e formação, no que tange a dimensão sexualidade. Para as autoras, é imperativo suprir necessidades formativas dos professores em processo de formação inicial e continuada diante das demandas sociais, que exigem desses sujeitos profundas reflexões sobre o tema em tela.

O capítulo cinco relata uma experiência internacional em educação sexual, desenvolvida cooperativamente entre instituições e profissionais de Portugal, Brasil e Moçambique, com objetivo de desenvolver no ambiente online o Curso de Formação "Educação Sexual sem Fronteiras: questões e factos contemporâneos". Os autores Graziela Pereira, Luciana Kornatzki, Paula Côrrea e Rui Marques Vieira, procuraram descrever os desafios de uma formação continuada, na modalidade a distância com alunos/as de licenciatura da Universidade Pedagógica (UP) localizada em Moçambique, utilizando como princípios norteadores os Direitos sexuais como Direitos Humanos, na busca de uma Educação Sexual emancipatória e libertadora. De acordo com os autores, os desafios encontrados durante o curso foram: o acesso precário à internet e, principalmente, as discussões provocadas pela cultura moçambicana acerca do modelo de educação sexual aplicado.

A revisão bibliográfica e a discussão proposta pelas autoras Camila D. de S. Figueiredo e Sonia Maria M. de Melo sobre o fenômeno Sexting em nossa sociedade é o objetivo do sexto capítulo. Neste estudo realizado durante a obtenção do título de mestre da profa. Camila, pelo PPGE/UDESC, as autoras levantam a problemática do fenômeno Sexting entre os adolescentes, alertando para uma reflexão que deverá ser 
feita junto a esses sujeitos sobre o uso das tecnologias digitais. A sugestão do estudo é mobilizá-los sobre os perigos de exposição de fotos, vídeos íntimos, nus e seminus nas redes sociais e o questionamento acerca da ausência de um processo de educação sexual emancipatória e intencional.

No capítulo sete, de autoria de Ricardo D. da Silva, Ana Cláudia B. Maia e Hertz W. de Camargo, é sustentada e desenvolvida uma proposta defendida na tese de doutoramento de um dos autores (SILVA, 2015) e que nesse livro é discutida como "uma nova percepção de estudo das imagens e sons na Educação Sexual na escola" e aponta a necessidade de metodologias adequadas para realizar o processo de ensino e aprendizagem, trazendo os recursos audiovisuais (vídeos) como alternativa. Propõe a necessidade de ultrapassar o seu uso ilustrativo e alerta para uma prática crítico-reflexiva e por isso dialógica, fazendo com que o aluno/a pense por e ressignifique o que foi apresentado, atribuindo sentido.

A discussão dos resultados de uma pesquisa qualitativa com a seguinte questão norteadora: "Como os adolescentes compreendem que ocorrem os seus processos de Educação Sexual hoje, em interfaces com as TIC?" é o tema principal do capítulo oito, da autora Enemari Salete Poletti. Sendo o foco do estudo o Google e suas relações com a educação sexual, a autora alerta para um uso acrítico das mídias pelos adolescentes/jovens, incentivando de certa forma o consumo e os modelos estereotipados de juventude disseminados por uma sociedade que se caracteriza por ser capitalista. A autora, então, propõe uma prática pedagógica dialógica, que escute as necessidades e demandas desses jovens/adolescentes e a urgência de uma educação sexual emancipatória e intencional.

O capítulo nove é uma análise pormenorizada do programa global "Sala de Emprego" desenvolvida pelas autoras Pâmela R. Jung e Mariléia M. da Silva, com o objetivo de refletir sobre a cultura midiática e o perfil do programa televisivo em questão, caracterizado como uma mídia de massa que influencia substancialmente as decisões políticas e sociais de seus telespectadores, principalmente, os jovens. 
O último capítulo (10) das autoras Ana Márcia de O. Carvalho e Maria Alves de T. Bruns, é estruturado em duas partes, sendo a primeira uma discussão sobre e questão de gênero e a contextualização da trajetória do movimento feminista no mundo, e a segunda, um interessante relato vivenciado pelas autoras no curso EAD "Gênero e Diversidade na Escola", no qual analisam as respostas a um questionário diagnóstico no "Módulo Gênero" pelos 500 professores participantes do curso. As autoras destacam a necessidade de se preencher uma lacuna na formação inicial e continuada dos professores, procurando fomentar mudanças diante das práticas discursivas de exclusão desses sujeitos e da diversidade que a dimensão sexualidade proporciona a todos os seres humanos.

Enfim, a obra é de extrema importância para educadores e professores que buscam refletir sobre a sua prática pedagógica e a urgência de uma educação sexual emancipatória que possibilite uma visão crítica do uso das tecnologias digitais por nossos adolescentes/jovens.

\section{Referências}

BRUNS, Maria Alves. T; MELO, Sônia Maria M. Desafios da educação sexual: interfaces pertinentes com comunicação e tecnologia. 1 ed. Curitiba, PR: CRV, 2016.

FREIRE, Paulo. Pedagogia do Oprimido. $17^{\mathrm{a} e d .}$ Rio de Janeiro: Paz e Terra, 1987.

Recebido em: 03/03/2016 Aprovado em: 12/03/2016

Universidade do Estado de Santa Catarina - UDESC Programa de Pós-Graduação em Educação - PPGE

Revista Linhas

Volume 17 - Número 33 - Ano 2016 revistalinhas@gmail.com 